WellBeing International

WBI Studies Repository

$5-1990$

\title{
Vocal Recognition of Pups by Mother Mexican Free-Tailed Bats, Tadarida brasiliensis mexicana
}

Jonathan P. Balcombe

University of Tennessee - Knoxville

Follow this and additional works at: https://www.wellbeingintlstudiesrepository.org/acwp_asie

Part of the Animals Commons, Comparative Psychology Commons, and the Other Animal Sciences

Commons

\section{Recommended Citation}

Balcombe, J.P. (1990). Vocal recognition of pups by mother Mexican free-tailed bats, Tadarida brasiliensis Mexicana. Animal Behavior, 39, 960-966.

This material is brought to you for free and open access by WellBeing International. It has been accepted for inclusion by an authorized administrator of the WBI Studies Repository. For more information, please contact wbisr-info@wellbeingintl.org.

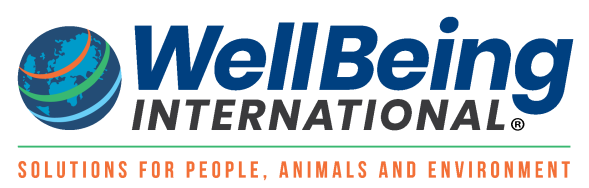




\title{
Vocal recognition of pups by mother Mexican free-tailed bats, Tadarida brasiliensis mexicana
}

\author{
Jonathan P. Balcombe \\ Graduate Program in Life Sciences (Ethology), M303 Walters Life Sciences Building, \\ University of Tennessee, Knoxville, TN 37996-0830, U.S.A.
}

\section{Recommended Citation:}

Balcombe, J.P. (1990). Vocal recognition of pups by mother Mexican free-tailed bats, Tadarida brasiliensis Mexicana. Animal Behavior, 39, 960-966.

\begin{abstract}
The ability of Mexican free-tailed bat mothers and pups to recognize vocalizations of their presumptive kin (pup isolation calls and mother echolocation calls, respectively) was tested using playbacks of recorded calls. Captive individuals were presented with calls of two bats, one presumptive kin and the other a stranger, from opposite sides of a circular wire arena. Response was determined by amount of time spent on each side of the arena, time spent in contact with a cloth bat model in front of each speaker, and number of separate contacts with each model. For the latter two measures, mothers showed a significant preference for the calls of their presumptive pups. Pups were attracted to adult echolocation calls, but did not show preference for calls of different mothers. The ages of pups appears to have had no effect on the responsiveness of either pups or mothers to the playbacks. This study demonstrates vocal kin recognition by mothers, and suggests an important role for acoustic cues in mother-pup reunions in this species. The findings do not preclude the possibility that vocal recognition of mothers by pups also occurs.
\end{abstract}

\section{NTRODUCTI ON}

Mechanisms of parent- offspring recognition should evolve in species where a parent invests heavily in its offspring, and where the potential exists for a parent to confuse its own young with others. Parent-offspring recognition has been documented for a number of vertebrates, including: gulls, Larus delawarensis (Evans 1980), swallows, Riparia riparia (Beecher et al. 1981), penguins, Pygoscelis adelae (Thompson \& Emlen 1968), monkeys, Saimiri sciureus (Kaplan et al. 1978), dolphins, Tursiops truncatus (Tavolga \& Essapian 1957), seals, Mirounga angustirostris (Petrinovitch 1974), reindeer, Rangifer tarandus (Espmark 1971) and bats, Myotis lucifugus (Thomson et al. 1985). For all of these examples, young of different parents intermingle, and rearing entails considerable costs to parents such as increased energy demands and/or risk of predation.

Pup-rearing in the Mexican free-tailed bat, Tadarida brasiliensis mexicana, represents an extreme scenario for the evolution of parent-offspring recognition. Pups, of which each mother has only one, are reared in creches that can number in the millions of individuals at densities up to 5000 per $\mathrm{m}^{2}$ (McCracken 1984). These crowded conditions led earlier 
researchers to conclude that nursing was random (Davis et al. 1962), but more recent work (McCracken 1984; McCracken \& Gustin 1987) showed that nursing within creches is nonrandom, and that mothers usually nurse their own pups. In addition, maternal investment is great. Mothers and pups reunite several times a day to nurse during the 5 weeks between birth and weaning. The energetic cost of lactation is known to be high in general (Millar 1977, 1978), and appears to be particularly so fer this species owing to their high milk loads and milk fat content (Davis et al. 1962; T. Kunz, personal communication).

Several cues appear to be involved in T. b. mexicana mother- pup reunions. Mothers exhibit spatial memory and repeatedly return to within $1 \mathrm{~m}$ of where they last left their pup (G. F. McCracken, personal communication). Mothers have also been shown to use olfactory cues in pup recognition (Gustin \& McCracken 1987). Pups are highly vocal and acoustic cues appear important for recognition by mothers. Gelfand \& McCracken (1986) examined several pup isolation call parameters and found them to be stereotyped within, and significantly variable among, individuals, features that suggest an adaptive role for individual recognition (Falls 1982).

While evidence of the attractiveness of infant vocalizations to mothers has been presented for many bat species (e.g. Pteropus poliocephalus, Nelson 1965; Eptesicus fuscus, Gould 1971; Desmodus rotundus, Schmidt 1972; Antrozous pallidus, Brown 1976; Carollia perspicillata, Porter 1979; Noctilio albiventris, Brown eta!. 1983; Myotislucifugus, Thomson et al. 1985), and these authors' claims of individual recognition are probably correct, few, if any, rigorous demonstrations of individual vocal recognition exist for bats. Evidence is often that mothers correctly retrieve their own calling pups, a situation for which other potentially useful sensory cues (e.g. olfaction) are also available.

The purpose of this study was to use the playback method to test the hypothesis that mother T. b. mexicana recognize the isolation calls of their pups. Since T. b. mexicana pups are mobile within crèches and may play an active role in the reunion process, I also tested the hypothesis that pups recognize the echolocation calls of their presumptive mothers; other bat studies have found evidence of reciprocal mother-pup recognition in Rousettus aegyptiacus (Kulzer 1958), Pteropus poliocephalus (Nelson 1965), Myotis lucifugus (Turner et al. 1972) and Rhinolophusferrumequinum (Matsumura 1981).

\section{METHODS}

\section{Subjects and Housing}

Forty-four bats (20 females, 24 pups) were captured and tested between 16 June and 26 July 1988. On most capture nights, three nursing mother-pup pairs were removed from the roost cave ceiling between 2330 and 0100 hours, after the mother had returned from foraging. Each pair was placed in a separate cloth bag. Following transport $(50 \mathrm{~km})$ to the research base, mothers and pups were separated and placed in numbered plastic cups with plastic screen lids and lining. A small wet sponge was placed in the bottom of each cup to provide moisture. Cups containing bats were kept in an insulated wooden room measuring $1.2 \times 1.2 \times 1.8 \mathrm{~m}$, equipped with heater, fan and thermostat to maintain temperatures 
around $33^{\circ} \mathrm{C}$ (similar to roost temperature). Mother-pup pairs were always separated for at least $3 \mathrm{~h}$ prior to a recording or playback session and reunited for at least $3 \mathrm{~h}$ following a session. Each pair was returned to the exact location of capture in the cave on or before the second night (at 2200 hours) after initial capture. Prior to release, the forearm length (elbow to wrist) of each pup was measured with a Vernier millimetre caliper. These measurements were used later to estimate pup ages (in days) by interpolating from the data of Short (1961), who also worked at Davis Cave. Whenever bats were handled, surgical gloves were worn to minimize the transfer of human odours.

\section{Recordings}

Recordings and playbacks were performed in a separate wooden room measuring $2-4 \times 1.8$ $x 1.8 \mathrm{~m}$. Bat calls were recorded onto tape $(13 \mu \mathrm{m})$ at $72 \mathrm{~cm} / \mathrm{s}$ using a Racal Store 4D reelto-reel tape-recorder, and a CM I mylar electrostatic microphone (QMC Electronics, London) directed at the recorded bat from a distance of $1 \mathrm{~m}$ and at a $30^{\circ}$ elevation angle to the animal. The signal was amplified with a QMC S200 Bat Detector and fed into the taperecorder. Recorded calls were monitored simultaneously using a Tektronix 212 dual channel oscilloscope. During all sessions, light ' was provided by a $25-\mathrm{w}$ red light mounted above the observer (myself), who sat $1.5 \mathrm{~m}$ from the subject.

Pup calls were recorded between 0600 and 0900 hours by placing the pup in the cup containing its mother. Pups usually (28 of 35 recording sessions) began calling within 5 min in this situation; mothers were invariably silent. I recorded the echolocation calls of each mother between 1500 and 1800 hours, by placing her in a circular wire screen arena measuring $46 \mathrm{~cm}$ in diameter $\times 7.5 \mathrm{~cm}$ ( Fig. 1) and allowing her to crawl around the arena for $5 \mathrm{~min}$. This also served to acclimate the mother bats to the playback apparatus. Pups were acclimated in a similar, smaller arena measuring $38 \mathrm{~cm}$ in diameter $\times 7.5 \mathrm{~cm}$.

\section{Playbacks}

Playback and control trials were run either in the morning (0600-0900 hours), or afternoon (1500-1800 hours). The apparatus used for these trials is shown in Fig. 1. At the start of a playback trial, the subject was placed in a plastic tube measuring $6 \mathrm{~cm}$ in diameter $\times 15 \mathrm{~cm}$, which opened into the arena away from the observer. The tube entrance was capped, and sound stimuli were switched on when the bat exited the tube into the arena. Each mother was presented with recorded calls of two pups, those of its own presumptive pup, and those of a strange pup. Similarly, each pup was presented with recorded echolocation calls of its own presumptive mother and those of a stranger. Each playback stimulus was played from one channel of the Racal tape-recorder, passed through an audio amplifier (model D255, York University Electronics, North York, Ontario), and broadcast through one of two speakers (Technics EAS10TH400B leaf tweeter). Each speaker was situated $1 \mathrm{~cm}$ outside the arena wall, one on the right and one on the left, each facing the centre of the arena (see Fig. 1). Playback stimuli were monitored on the oscilloscope to ensure similar signal intensities. The arena floor was covered with a clean sheet of white bristol board with a black line delineating right and left halves. To minimize further possible effects of odours on 
the behaviour of subjects, mother and pup playbacks were performed using separate arenas, entrance tubes and models (see below).

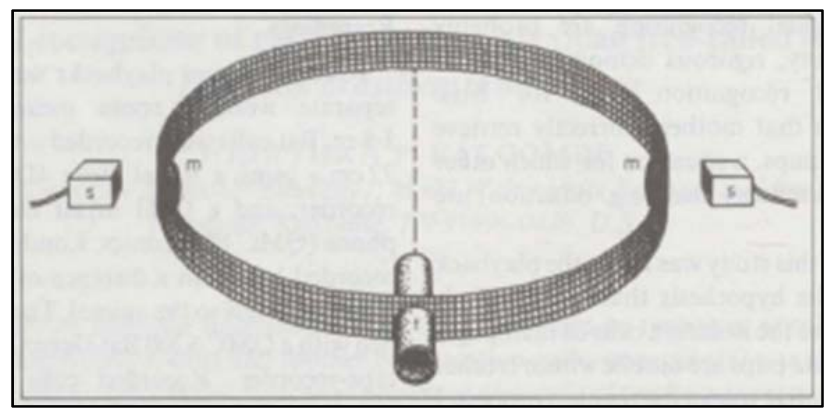

Figure 1. Arena apparatus used in playback and control trials, with wire-screen arena lid removed. s: speaker; $\mathrm{t}$ : entry tube; m: model.

Pup playbacks lasted $5 \mathrm{~min}$; mothers, who tended to acclimate less quickly to the arena, were given 10-min playbacks. In addition to a playback trial, each bat was tested in a control trial, identical to a playback except that blank tape was played through each speaker. The purpose of controls was to allow comparison with playbacks to ensure that bats were indeed responding to the sound stimuli (see Data below). The side from which the two playback stimuli were presented and the side on which each model was placed were determined by coin toss, as was the order of playback and control trials for each bat. The same observer scored all trials in the study and all trials were performed 'blind', with only an assistant knowing the assignment of stimuli to the speakers. A bat was given only one trial per session. At the end of playback or control trials, mother-pup pairs were reunited.

During preliminary tests, subjects evinced apparent interest in the calls, but would not stay near the speaker. I interpreted this as possibly resulting from the lack of a physical goal associated with the sound stimulus; for instance, a mother bat responding to calls of her pup should not stop searching until she contacts the pup. In an attempt to alleviate this possible problem, I constructed four bat 'models' and placed one directly in front of each speaker on the inside wall of the arena. Models were made of wiping cloth stuffed with cotton wool, and were rubbed together against the cave roost ceiling to give them a 'batty' odour. The two models used in playbacks to mothers were the size of a typical pup, measuring $18 \times 15 \times 45 \mathrm{~mm}$; the two used in playbacks to pups were adult-sized, measuring $30 \times 25 \times 75 \mathrm{~mm}$.

\section{Data}

I scored three measures for each bat during playbacks and controls: (1) time (s) spent in each side of the arena, (2) time spent in contact with each model, and (3) number of separate contacts with each model. To assess responses to playback stimuli, I computed a difference score of each measure for each bat by subtracting the non-kin-side score (strange mother or pup) from the kin-side score (own presumptive mother or pup). The null hypothesis that the mean of the difference scores for each experiment was equal to zero, was tested with a one-tailed t-test (SAS Institute 1985). 
To test that bats were responding to the sound stimuli in the playbacks (and not, for instance, only to the model odours), I compared the results from playback trials with those from controls using two different scores as follows. The first score was the total amount of time in contact with both models during the playback trial minus total time in contact with both models during the control trial. The second score was total number of contacts with both models during the playback trial minus total contacts during the control trial. I used a one-tailed t-test to compare the mean of the difference scores for all individuals (mothers or pups) to the null hypothesis that the difference was equal to zero. To examine the possibility that responses of pups and mothers to vocal stimuli might change with pup age, I performed regression analyses (SAS Institute 1985; Proc REG) on the data from pup and mother playbacks, using pup age as the independent variable, and difference score for time spent in contact with each model as the dependent variable. Statistical significance was designated at $\mathrm{P}<0.05$ for all tests.

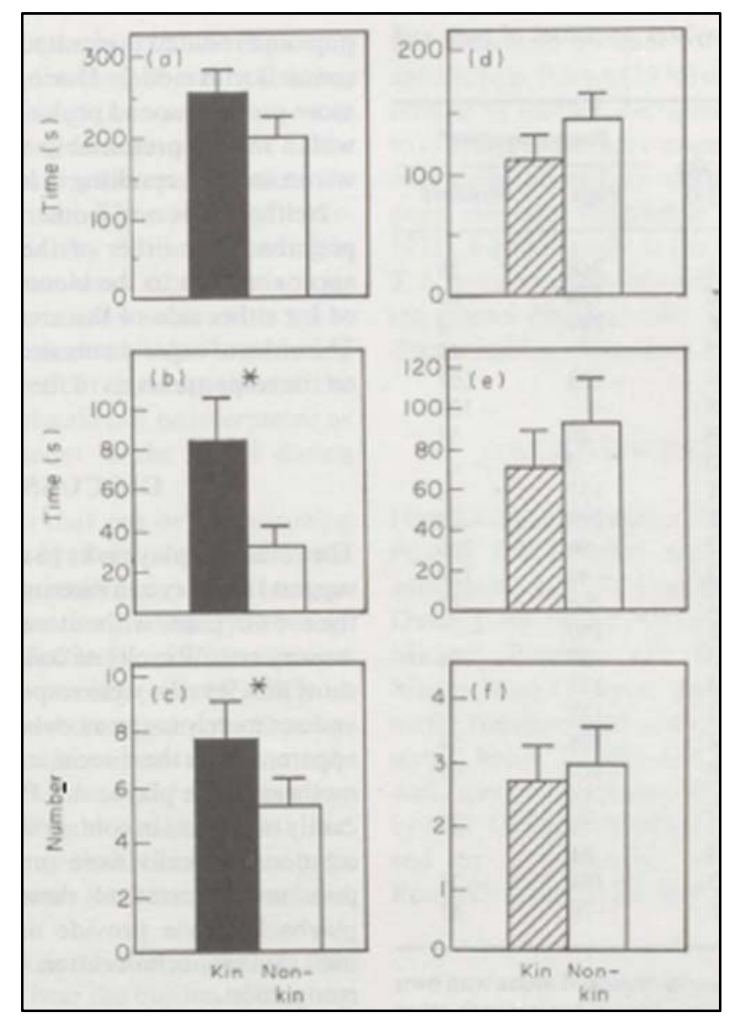

Figure 2. Mean responses of $T$. b. mexicana mothers to playbacks of pup isolation calls: (a) time spent on each side of arena ( $N=20 ; P>0.20)$; (b) time spent in contact with models ( $N=18 ; \mathrm{P}<0.02)$; (c) number of separate contacts with models $(N=18 ; P<0.03)$; and of pups to playbacks of mother echolocation calls: (d) time spent on each side of arena $(\mathrm{N}=24 ; \mathrm{P}>0-40)$; (e) time spent in contact with models $(\mathrm{N}=24 ; \mathrm{P}>0.50)$; (f) number of separate contacts with models $(\mathrm{N}=24 ; \mathrm{P}>0.50)$. See Methods for explanation of means.* $\mathrm{P}<0.05$. Vertical bars are $+1 \mathrm{SE}$.

\section{RESULTS}

For two of the three measures, time in contact with model and number of contacts with model, mothers significantly preferred the calls of their own presumptive pup to those of a strange pup (Fig. $2 \mathrm{~b}, \mathrm{c}$ ). Mothers also spent more time on the side of the arena towards 
their own pup's calls (Fig. 2a), but the difference was not statistically significant. Pups showed no preference for the echolocation calls of their own mother versus those of a strange mother for any of the three measures (Fig. 2d, e, f).

For the comparison of playback versus control trials, mothers $(\mathrm{N}=18)$ spent significantly more time $(X \pm s E)$ in contact with models ( $123.1 \pm 23.4$ versus $33.5 \pm 7.5 \mathrm{~s} ; \mathrm{P}<0.001$ ), and made significantly more separate contacts per bat with models $(13 \cdot 1 \pm 2 \cdot 0$ versus $9 \cdot 0 \pm 2 \cdot 1$; $\mathrm{P}<0.05)$ during playbacks than during control trials. Pups $(\mathrm{N}=22)$ also spent significantly more time in contact with the two models during playback trials than during control trials (163-4 \pm 20.5 versus $106.0 \pm 19.5 \mathrm{~s} ; \mathrm{P}<0.03$ ), but there was no significant difference in the number of separate contacts with models $(5 \cdot 7 \pm 1 \cdot 1$ versus $7 \cdot 3 \pm 1 \cdot 5 ; \mathrm{P} 0 \cdot 1)$.

Table 1. Pup ages and playback responses of pups and mothers used in this study

\begin{tabular}{|c|c|c|c|}
\hline \multirow{2}{*}{$\begin{array}{l}\text { Pup } \\
\text { forearm length } \\
\text { (mm) }\end{array}$} & \multirow{2}{*}{$\begin{array}{l}\text { Pup age } \\
\text { (days) }\end{array}$} & \multicolumn{2}{|c|}{ Response score* } \\
\hline & & Pups & Mothers \\
\hline $15 \cdot 2$ & 1 & 268 & 28 \\
\hline $21 \cdot 2$ & 6 & 198 & -86 \\
\hline $21 \cdot 6$ & 6 & -299 & 8 \\
\hline & 7 & - & 45 \\
\hline $23 \cdot 6$ & 8 & -128 & 107 \\
\hline $24 \cdot 2$ & 8 & - & -109 \\
\hline 25.7 & 9 & -10 & 68 \\
\hline 260 & 10 & 0 & - \\
\hline 27.8 & 11 & 132 & 8 \\
\hline $28-0$ & 11 & -209 & -14 \\
\hline 28.8 & 12 & -56 & 266 \\
\hline $29-1$ & 12 & -44 & 129 \\
\hline 29.4 & 12 & 286 & 21 \\
\hline $30-9$ & 13 & 140 & - \\
\hline $31-0$ & 13 & 27 & 174 \\
\hline $31 \cdot 4$ & 14 & -277 & \\
\hline 31.7 & 14 & -127 & - \\
\hline $31-9$ & 14 & -195 & 54 \\
\hline 33.7 & 16 & -110 & 60 \\
\hline $34-0$ & 16 & -16 & \\
\hline $35-0$ & 17 & 76 & 39 \\
\hline 36.2 & 18 & 61 & \\
\hline 38.8 & 23 & -184 & -28 \\
\hline $41-0$ & 36 & -20 & 81 \\
\hline
\end{tabular}

*Time (s) in contact with model on side of arena with own presumptive kin's calls, minus time in contact with other model.

Ages of pups in this study ranged from 1 to 36 days $(X=13 \cdot 0)$ (Table 1$)$. No effect of pup age on responses to playbacks was found for either pups ( $2=0.03, F=0 \cdot 72, N=22, P>0 \cdot 5$ ) or mothers $(r 2=0.02, F=0-41, N=18, P>0.5)$.

The behaviour of bats in the arenas was usually suggestive of response towards presented stimuli. Particularly during playbacks, bats showed distinct interest in the models, orienting towards them, crawling atop them, and frequently coming to rest beneath or behind them. At times, mothers scrambled about hastily in a non-directed fashion and appeared more interested in trying to escape the arena, but this did not usually persist beyond the first 3 min of a trial. In some trials, the subject would crawl around the arena periphery for a time, making brief contacts with a model as it passed them. This was common during control trials with pups and resulted in elevated scores for numbers of contacts with models. During 
playbacks, pups were more prone to spend prolonged periods in contact with a model, presumably treating it as though it were a mother, resulting in less separate contacts.

Neither pups nor mothers showed a significant preference for either of the two models (normal approximation to the binomial, $N=54, P>0.07$ ), or for either side of the arenas $(\mathrm{N}=85, \mathrm{P}>0.07)$. The order of experiments and controls had no effect on the response levels of the bats.

\section{DISCUSSION}

The results of playbacks to mother T. b. Mexicana suggest that they can discriminate isolation calls of their own pups without reference to any other sensory cues. Results of controls versus playbacks show that females were responding to vocal stimuli and not merely to the models, though this is already apparent from the discriminating behaviour of the mothers in the playbacks. Pups also spent significantly more time in contact with models when adult echolocation calls were present, suggesting that pups are attracted to these calls. However, the playbacks alone provide no evidence that pups use mother echolocation calls for individual recognition.

There is also no evidence from this study that pup or mother responsiveness to vocalizations changes as pups grow older, although the calls presented to pups (mother echolocation) were probably inappropriate to address this issue (see below). Pups do become much more mobile as they age, and appear to play a more active role in reunion searches (McCracken, unpublished data; personal observation) as has been reported for Phyllostomus discolor (Esser \& Schmidt 1989). Whether there is any age-based increase in vocal recognition ability, however, as Thomson et al. (1985) have suggested for Myotis lucifugus, remains unresolved for T. b. mexicana.

Of the three measures I used to score bat responses, the amount of time spent in contact with models probably best represents the bats' reactions to the stimuli. For the most part, scores for this measure reflect actual responses toward the sound stimuli presented, as indicated by the directed behaviour of bats toward the models. The other two measures were somewhat more ambiguous. Any time that a bat was not responding to the sound stimuli (for example, when it was exploring or trying to escape the arena), it was still being scored for whichever side of the arena it was on at the time. For this reason, time on each side of the arena probably is a less accurate representation of a bat's response to the stimuli. The number of separate contacts with models may also be misleading in some cases. The lower number of model contacts by pups during playbacks relative to controls probably reflects their less directed behaviour during control trials (i.e. repeated crawling around the arena periphery), and should not be interpreted as meaning a greater interest in the model during control trials.

The possibility exists that one or more nursing pairs used in this study were not in fact true mother-pup pairs. My results may thus be conservative estimates of mothers' accuracy in recognition of pup calls. McCracken (1984) reported that about $17 \%$ of the nursing pairs $(\mathrm{N}=167)$ he examined could not have been parent-offspring. Tadarida brasiliensis mexicana 
pups are commonly aggressive in their efforts to obtain milk from any mother (Davis eta!. 1962; McCracken 1984), and unrelated nursing pairs probably result from pups successfully latching onto the teats of unrelated mothers.

Gustin \& McCracken (1987) suggested that mother T. b. mexicana bear the burden of locating and selecting the pups they nurse, because the pups they tested did not show olfactory discrimination of different mothers, and because pups attempt to nurse any available female. While results of my study appear to support this suggestion, there is preliminary evidence, from video recorded mother-pup searches inside caves, that pups recognize presumptive mothers and that acoustic cues are involved (McCracken \& Gustin, unpublished data). During their searches, mothers periodically open their mouths in a manner suggesting a rapid burst of intense vocal pulses, quite unlike the typical echolocation call of this species. In addition, during six successful mother-pup searches recorded on video, the target pup in each case moved several centimetres towards its presumptive mother (McCracken \& Gustin, unpublished data). In my playbacks, pups were presented only with echolocation calls and it is uncertain whether mothers use echolocation during pup searches. Mother T. b. mexicana search for their pups by landing on the edge of a creche and crawling through the cluster of pups; echolocation is probably of limited value in this situation, at least for the recognition of a specific pup. Brown (1976) described a directive call uttered by mother Antrozous pallidus that appears to function in mother recognition by pups. Doublenote calls, uttered by mothers in the presence of pups, may also function in this way (Gould et al. 1973). Further study of the role of vocalizations in T. b. mexicana reunions will be aimed at documenting mother directive calls, and testing their role in discrimination of mothers by pups.

\section{ACKNOWLEDGMENTS}

I thank Gary McCracken, Shahroukh Mistry, Hugh Powell, Jim Loughry and Ty Burnette for field assistance, and Gould and Billie Davis for access to Davis Cave. Gary McCracken, Brock Fenton, Michael Beecher, Lee Drickamer, Shahroukh Mistry, Matt Gompper and Chris Boake provided useful comments on earlier versions of the manuscript. Brock Fenton and Jack Bradbury generously loaned equipment. This study was supported by NSF Grant BSR8700425 to G. F. McCracken, and by a University of Tennessee Ethology Research Grant to the author.

\section{REFERENCES}

Beecher, M.D., Beecher, I. M. \& Hahn, S. 1981. Parent-offspring recognition in bank swallows (Riparia riparia): II. development and acoustic basis. Anim. Behav., 29,95- 101.

Brown, P. 1976. Vocal communication in the pallid bat, Antrozous pallidus. Z. Tier psychol., 41, 34-54.

Brown, P., Brown, T. W. \& Grinnell, A. D. 1983. Echolocation, development, and vocal communication in the lesser bulldog bat, Noctilio albiventris. Behav. Ecol. Sociobiol., 13, 287-298. 
Davis, R. B., Herried II, C. F. \& Short, H. L. 1962. Mexican free-tailed bats in Texas. Eco/. Monogr., 32, 311-346.

Espmark, Y. 1971. Individual recognition by voice in reindeer mother-young relationship. Field observation and playback experiments. Behaviour, 40, 295- 301.

Esser, K. H. \& Schmidt, U. 1989. Mother- infant communication in the lesser spear-nosed bat Phyllostomus discolor (Chiroptera, Phyllostomidae): evidence for acoustic learning. Ethology, 82, 156-168.

Evans, R. M. 1980. Development of individual call recognition in young ring-billed gulls (Larus delawarensis): an effect of feeding. Anim. Behav., 28, 60-67.

Falls, J. B. 1982. Individual recognition by sounds in birds. In: Acoustic Communication in Birds. Vol. 2 (Ed. by D. E. Kroodsma \& E. H. Miller), pp. 237-278. New York: Academic Press.

Gelfand, D. L. \& McCracken, G. F. 1986. Individual variation in the isolation calls of Mexican free-tailed bat pups (Tadarida brasiliensis mexicana). Anim. Behav., 34, 1078-1086.

Gould, E. 1971. Studies of maternal-infant communication and development of vocalizations in the bats Myotis and Eptesicus. Comm. Behav. Bioi., 5, 263-313.

Gould, E., Woolf, N. K. \& Turner, D. C. 1973. Doublenote communication calls in bats: occurrence in three families. J. Mammal., 54, 998-1001.

Gustin, M. K. \& McCracken, G. F. 1987. Scent recognition in the Mexican free-tailed bat, Tadarida brasiliensis mexicana. Anim. Behav., 35, 13-19.

Kaplan, J. N., Winship-Ball, A. \& Sim, L. 1978. Maternal discrimination of infant vocalizations in squirrel monkeys. Primates, 19, 187-193.

Kulzer, E. 1958. Untersuchungen iiber die Biologie von Flughunden der Gattung Rousettus. Z. Morphol.Oekol.Tiere., 47,374-402.

McCracken, G. F. 1984. Communal nursing in Mexican free-tailed bats. Science, N.Y., 223, 1090-1091.

McCracken, G. F. \& Gustin, M. K. 1987. Bat moms' daily nightmare. Nat. Hist., 10, 66-72.

Matsumura, S. 1981. Mother-infant communication in a horseshoe bat (Rhinolophus ferrumequinum nippon): vocal communication in three-week old infants. J. Mammal., 62, 20-28.

Millar, J. S. 1977. Adaptive features of mammalian reproduction. Evolution, 81, 370-386. 
Millar, J. S. 1978. Energetics of reproduction in Peromyscus leucopus: the cost oflactation. Ecology, 59, 1055-1061.

Nelson, J. E. 1965. Behaviour of Australian Pteropodidae (Megachiroptera). Anim. Behav., $13,544-557$.

Petrinovich, L. 1974. Individual recognition of pup vocalizations by northern elephant seal mothers. z. Tierpsychol., 34,308-312.

Porter, F. L. 1979. Social behavior in the leaf-nosed bat Carollia perspicillata. II. Social Communication. z. Tierpsychol., 50, 1-8.

SAS Institute. 1985. SAS User's Guide: Statistics. Cary, North Carolina: SAS Institute.

Schmidt, U. 1972. Social calls of juvenile vampire bats (Desmodus rotundus) and their mothers. Bonn. Zool. Beitr., 4, 310-316.

Short, H. L. 1961. Growth and development of Mexican free-tailed bats. Southw. Nat., 6, 156-163.

Tavolga, M. C. \& Essapian, F. S. 1957. The behavior of the bottle-nosed dolphin (Tursiops truncatus): mating, pregnancy, parturition and mother-infant behavior. Zoologica, 42, 1131.

Thompson, D. H. \& Emlen, J. T. 1968. Parent-chick individual recognition in the Adelie penguin. Antarct. J., 3, 132.

Thomson, D. E., Fenton, M. B. \& Barclay, R. M. R. 1985. The role of infant isolation calls in mother-infant reunions in the little brown bat, Myotis lucifugus (Chiroptera: Vespertilionidae). Can. J. Zool., 63, 1982-1988.

Turner, D., Shaughnessy, A. \& Gould, E. 1972. Individual recognition between mother and infant bats (Myotis). In: Animal Orientation and Navigation (Ed. by S. R. Galler, SchmidtKoenig, D., Jacobs, G. J. \& Belleville, R. E.), pp. 365-371. Washington, D.C.: NASA SP-262.

(Received 7 June 1989; initial acceptance 13 July 1989;

final acceptance 24 August 1989;

MS. number: A5585) 